J. Clin. Chem. Clin. Biochem.

Vol. 26, 1988, pp. 857-861

(C) 1988 Walter de Gruyter \& Co.

Berlin - New York

\title{
A Reevaluation of Choline Acetyltransferase Activity in Human Cerebrospinal Fluid and Serum
}

\author{
By $M$. Mäder and $U$. Dickmann \\ Neurologische Klinik der Universität Göttingen
}

(Received November 4, 1987//March 31/September 12, 1988)

Summary: Choline acetyltransferase (EC 2.3.1.6) was studied in human cerebrospinal fluid and blood. Sensitivity, precision and reproducibility of the radioactive assay were evaluated with a homogenate from pig brain and with partially purified enzymes from bovine brain and human placenta. Contrary to other reports, with the assay used in the present study, choline acetyltransferase activity was not detectable in the cerebrospinal fluid or blood of 50 patients with various neurological disorders. Only a very slight but significant non-enzymatic formation of a radioactive product by concentrated cerebrospinal fluid was observed. Nonenzymatic but enzyme-like formation of acetylcholine by thiol reagents and other compounds is discussed.

\section{Introduction}

So far, only a few attempts, with conflicting results, have been made to detect choline acetyltransferase activity in human cerebrospinal fluid and blood $(1-3)$. As choline acetyltransferase is regarded to be specifically localized in cholinergic neurons, its changes in cerebrospinal fluid and serum might reflect destruction of nervous tissue (4).

Previously, choline acetyltransferase activity was determined preferentially by radiochemical methods. Labeled acetylcholine is formed from labeled acetylCoA and choline $(5-7)$. The labeled product has to be separated from the labeled substrate. This was achieved by ion exchange chromatography, two phase extraction and by combining both techniques. These procedures are time consuming and cumbersome, which may well explain the lack of investigations of choline acetyltransferase activity in human body fluids (4).

In 1975 Fonnum (8) published an improved method for choline acetyltransferase measurement which involves liquid cation exchange in a two-phase system with direct counting. This is achieved by using the toluene scintillation-mixture as an extraction solvent and by carrying out the extraction directly in the scintillation vial. This method was supposed to be rapid, precise and sensitive (8). We considered it worthwhile to attempt the detection of choline acetyltransferase activity in cerebrospinal fluid and serum with the improved method.

\section{Materials and Methods}

Chemicals

Choline bromide, eserine (physostigmine) and tetraphenylboron were purchased from Sigma (München). EDTA (ethylenedinitrilo) tetraacetic acid, sodium salt, (Titriplex III), acetonitrile, toluene and salts for preparing buffers were purchased from Merck (Darmstadt). Cibacron Blue F3GA (C. I. Reactive Blue, Procion Blue H-BS) was purchased from Serva (Heidelberg). Acetyl-Coenzyme A (acetyl-CoA) was purchased from Boehringer (Mannheim). Coenzyme A (acetyl- $1-{ }^{14} \mathrm{C}$ ) acetyl (1.48 - 2.22 GBq/mmol) and Omnifluor (pre-mixed LSC Powder) were purchased from NEN (New England Nuclear, Dreieich). Choline acetyltransferase partially purified from bovine brain (lyophilized powder containing 5-20\% protein) and from human placenta (suspension in $\left.2.8 \mathrm{~mol} / \mathrm{l}\left(\mathrm{NH}_{4}\right)_{2} \mathrm{SO}_{4}\right)$ were purchased from Sigma (München).

\section{Enzyme preparation}

Whole pig brains from the slaughter house were placed on ice within $30 \mathrm{~min}$ after death. All subsequent procedures were carried out at $4^{\circ} \mathrm{C}$. After removal of the meninges and addition of 11 extraction medium (phosphate-buffered saline $\mathrm{pH} 5.0$ ), 
the brains $(572 \mathrm{~g})$ were homogenized with an Ultra Turrax (Janke \& Kunkel, Staufen). The homogenate was centrifuged $(20$ min, $2500 \mathrm{~g})$, the supernatant was discarded and the pellet was dissolved in phosphate buffer $\mathrm{pH} 7.4$ with Triton $(5 \mathrm{~g} / \mathrm{l})$ added. After centrifugation $(20 \mathrm{~min}, 25000 \mathrm{~g})$ the pellet was discarded and the supernatant brought to $60 \%$ saturation with solid $\left(\mathrm{NH}_{4}\right)_{2} \mathrm{SO}_{4}$, stirred for $30 \mathrm{~min}$ and centrifuged again (20 min, $25000 \mathrm{~g}$ ). The pellet was dissolved in $40 \mathrm{ml} 50 \mathrm{mmol} / \mathrm{l}$ sodium phosphate buffer $\mathrm{pH} 7.4$ and dialysed overnight against the same buffer with one change of buffer. The crude enzyme preparation (pig brain) was then stored in aliquots below $-25^{\circ} \mathrm{C}$.

\section{Enzyme assay}

Choline acetyltransferase activity was assayed according to the method of Fonnum (8) with minor modifications. The final volume of the reaction mixture was $10 \mu$ containing $1,85 \mathrm{kBq}$ (50 nCi) $\left[{ }^{14} \mathrm{C}\right]$ acetyl CoA, $0.4 \mathrm{mmol} / 1$ acetyl $\mathrm{CoA}, 300 \mathrm{mmol} / \mathrm{l}$ sodium chloride, $50 \mathrm{mmol} / \mathrm{l}$ sodium phosphate buffer $\mathrm{pH} 7.4$, $8 \mathrm{mmol} / \mathrm{l}$ choline bromide, $20 \mathrm{mmol} / \mathrm{l}$ EDTA (pH 7.4) and 0.1 $\mathrm{mmol} / \mathrm{l}$ physostigmine. Enzyme solution $(2.5 \mu \mathrm{l})$ was added to the substrate solution $(7.5 \mu \mathrm{l})$ in $0.5 \mathrm{ml}$ Eppendorf tube. The tubes were placed in a water bath at $22^{\circ} \mathrm{C}$ or $37^{\circ} \mathrm{C}$. The reaction was stopped after $10 \mathrm{~min}$ (if not stated otherwise) by addition

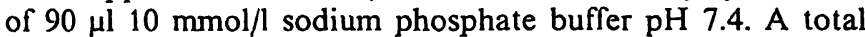
of $100 \mu \mathrm{l}$ was then transferred to a scintillation vial $(20 \mathrm{ml})$ containing $5 \mathrm{ml} 10 \mathrm{mmol} / \mathrm{l}$ sodium phosphate buffer $\mathrm{pH} 7.4$. Acetonitrile $(2 \mathrm{ml})$ containing $10 \mathrm{mg}$ tetraphenylboron was added and after brief mixing, $10 \mathrm{ml}$ toluene scintillation mixture were then added. The vials were shaken slightly for 15 seconds and the two phases were allowed to separate for 10 minutes before counting.

\section{Results and Discussion}

To measure choline acetyltransferase activity the very sensitive assay method of Fonnum (8) which is widely accepted today (9) was adapted with minor modifications (see Material and Methods). This radioactive assay involves three major steps: incubation of reaction mixture, separation of radioactive product from radioactive substrate and $\beta$-counting. Each step has to be controlled separately and in combination with the other two. To make sure that the Fonnum assay was working under optimal conditions we checked it with enzyme standards from pig brain homogenates (see Materials and Methods). In figure 1 the relationship between product formation, amount of enzyme, time and temperature under optimal conditions is shown. The typical decrease of the reaction velocity of choline acetyltransferase after $20 \mathrm{~min}$, due to enzyme inhibition by accumulation of free Coenzyme $\mathrm{A}$ (6), is also depicted in figure 1. Measurements with pig brain homogenates were found to be similar to those with partially purified enzymes from human placenta or bovine brain.

When testing choline acetyltransferase activity in pooled fractions of cerebrospinal fluid and serum (10 patients each) we could not detect any formation of radioactive acetylcholine, either in unboiled or boiled samples (3). Tenfold concentrated body fluids also showed no activity in the assay. Our results are thus, at first glance, in contradiction to those of 1.c. $(1-3)$. These authors report extremely low amounts of acetylcholine formed in cerebrospinal fluid. But Aquilonius \& Eckernas (3) suggested that about $95 \%$ of the product measured was due to non-enzymatic conversion of the substrate.

Due to these ambiguous results we studied choline acetyltransferase activity in cerebrospinal fluid and serum in more detail. When partially purified enzyme from human placenta or bovine brain was added either to cerebrospinal fluid, serum or phosphate buffer, choline acetyltransferase activity stayed unchanged at $4{ }^{\circ} \mathrm{C}$ for 7 days and at $22^{\circ} \mathrm{C}$ for 24 hours (data not shown). As choline acetyltransferase activity is usually measured at $37^{\circ} \mathrm{C}$, we incubated samples
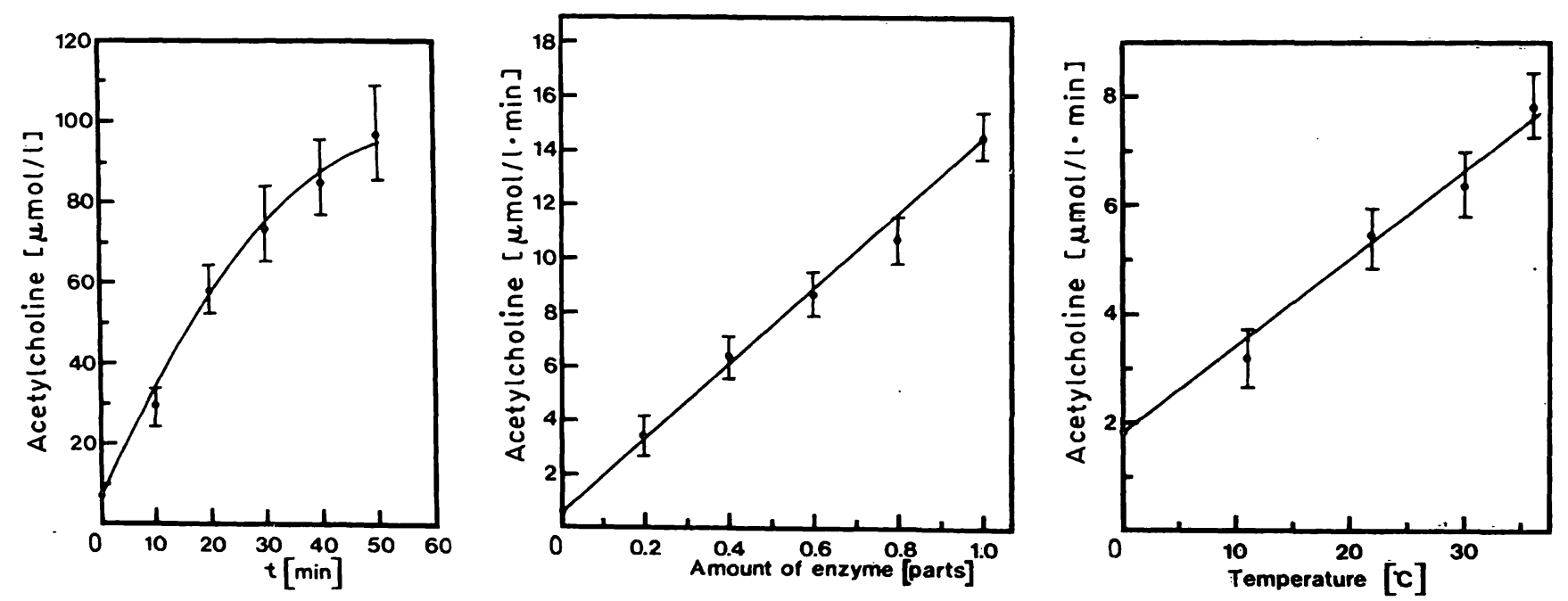

Fig. 1. Acetylcholine formation by pig brain homogenate in relation to time, amount of enzyme (parts of enzyme preparation) and temperature as monitored by the Fonnum assay (see Materials and Methods) under optimal conditions. The reaction time was $10 \mathrm{~min}$ if not otherwise indicated. 


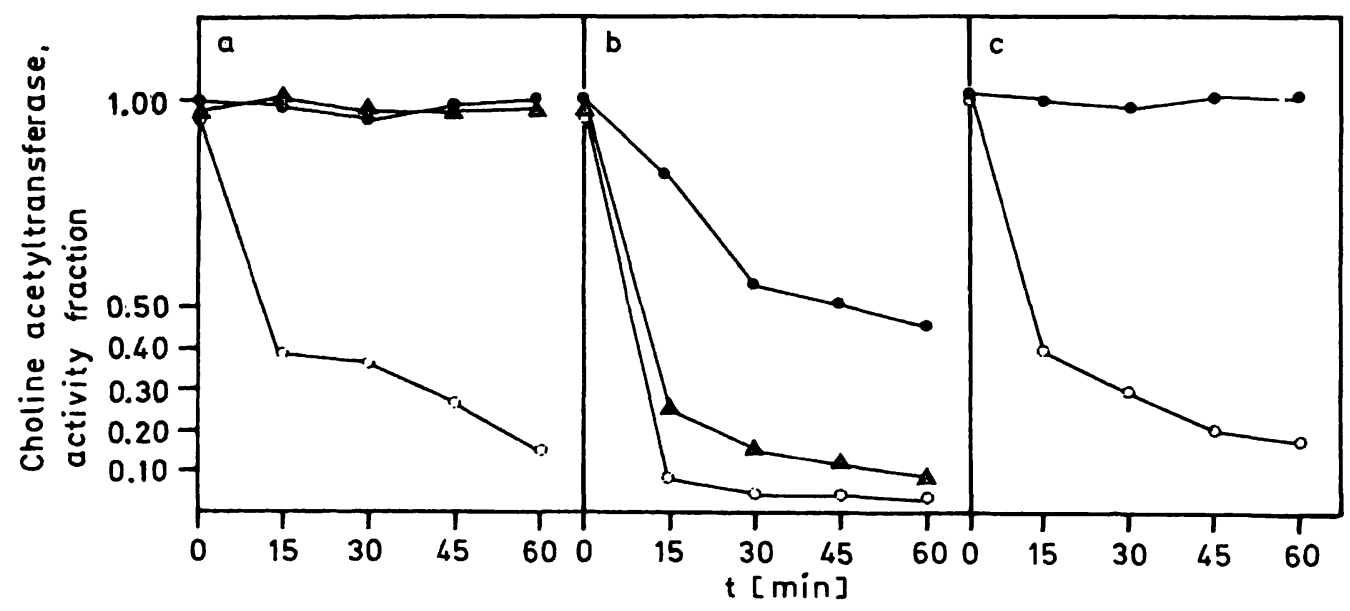

Fig. 2. Stability of choline acetyltransferase

a) Incubation of enzyme from human placenta in phosphate buffer at $0^{\circ} \mathrm{C}-\Theta-, 22{ }^{\circ} \mathrm{C}-\Delta-, 37^{\circ} \mathrm{C}-0-$.

b) Incubation of enzyme from pig brain - - , bovine brain $-\Delta-$, and human placenta $-0-$ in serum at $37^{\circ} \mathrm{C}$.

c) Incubation of enzyme from human placenta in cercbrospinal fluid with dithiothreitol $(1 \mathrm{mmol} / \mathrm{l})-0-$ and without dithiothreitol $-\mathrm{O}-$ at $37^{\circ} \mathrm{C}$.

at $0{ }^{\circ} \mathrm{C}, 22^{\circ} \mathrm{C}$, and $37^{\circ} \mathrm{C}$ for 1 hour and recorded choline acetyltransferase activity every 15 minutes. A sharp decline of choline acetyltransferase is noticed (fig. 2 a) at $37^{\circ} \mathrm{C}$. This applies particularly to serum and cerebrospinal fluid (data not shown). The decline of enzyme activity is fastest for human placenta followed by bovine brain and pig brain (fig. $2 \mathrm{~b}$ ). The degree of acetyltransferase inactivation is thus due to the matrix (serum, cerebrospinal fluid or buffer) and to the source of enzyme. When using preheated $\left(70^{\circ} \mathrm{C}, 30 \mathrm{~min}\right)$ body fluids the decrease of choline acetyltransferase did not alter. Thus, the biological inactivation of acetyltransferase (e.g. by proteases) can be ruled out.

We noticed then that pig brain homogenates prepared by addition of thiol reagents ( $\beta$-mercaptoethanol or dithiothreitol) were less or not at all affected in the experiments described above. Thiol reagents are regularly used in choline acetyltransferase purification procedures to stabilize the enzyme $(10,11)$. When thiol reagents (e.g. $1 \mathrm{mmol} / \mathrm{l}$ dithiothreitol) are added to serum or cerebrospinal fluid before the enzyme the decrease of activity is completely stopped as shown in figure $2 \mathrm{c}$. From this result we draw the conclusion that some labile thiol groups of the enzyme $(10,12)$ will be oxidized chemically in body fluids at $37^{\circ} \mathrm{C}$ if not protected sufficiently by addition of a thiol reagent. This suggestion is in good accord with the fast decline of enzyme activtiy immediately after incubation (fig. 2). Inactivation of choline acetyltransferase in body fluids may be explained in this way. The various degrees of inactivation that occurred with the partually purified enzymes from different species may be explained by different quantities and qualities of inherent protecting factors. It is well known $(12,9)$ that choline acetyltransferase becomes more and more labile during purification if thiol reagents are not added.

We do not know whether acetyltransferase inherent in body fluids - if existing at all - will be protected from autoxidation. Addition of thiol reagents to body fluids immediately after tapping in order to stabilize inherent choline acetyltransferase seems not advisable because thiol reagents themselves produce choline acetyltransferase-like activity in the Fonnum assay as shown in figure 3. This fact has to our knowledge not been described to date in the literature. The choline acetyltransferase-like activity depends linearly on the amount of thiol reagent and the reaction time (fig. 3). As Roskoski et al. (12) suggest, an acetyl-thioenzyme may be involved as an intermediate in the choline acetyltransferase reaction mechanism. It seems that thiol reagents may replace this intermediate by possible forming an acetyl thio-compound. The latter has not been characterized. Acetyltransferase-like activity was low when $1 \mathrm{mmol} / \mathrm{l}$ or less thiol reagent was used (fig. 3), and therefore it was negligible in the experiments described above where high amounts of enzyme activity were added to the body fluids. But thiol reagents will cause serious problems if traces of inherent choline acetyltransferase activity are to be measured. The minimum amount of dithiothreitol for stabilizing choline acetyltransferase (human placenta) in cerebrospinal fluid during $20 \mathrm{~min}$ is $0.1 \mathrm{mmol} / \mathrm{l}$. Even this amount produces measurable quantities of radioactive acetylcholine (fig. 4).

In the following investigations the body fluids were cooled to $4{ }^{\circ} \mathrm{C}$ or frozen at $-25^{\circ} \mathrm{C}$ immediately after veni or lumbar puncture of the patients. Before testing choline acetyltransferase activity in cerebrospinal 


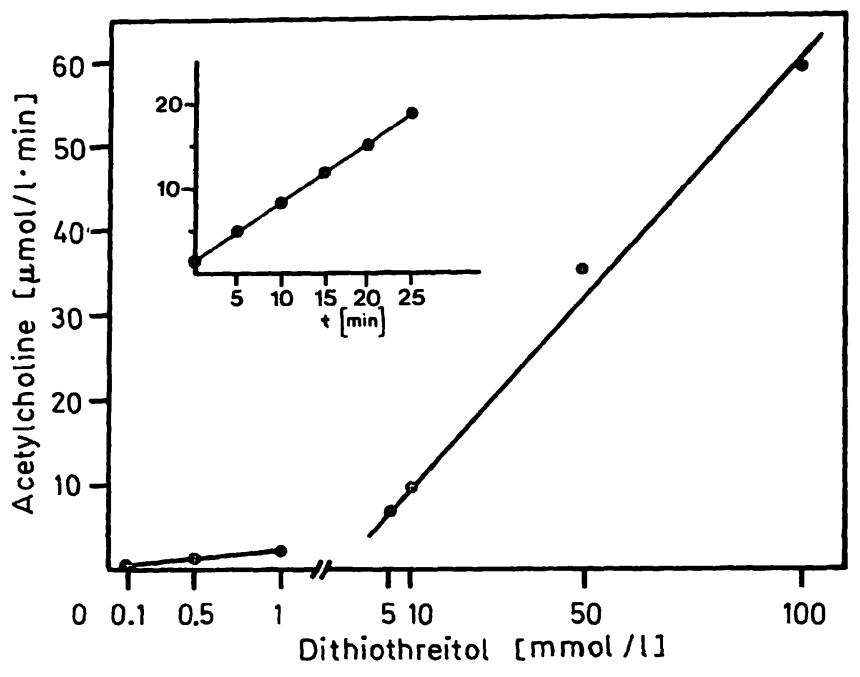

Fig. 3. Non-enzymatic acetylcholine formation in the presence of dithiothreitol in relation to its concentration and the reaction time (insert, $5 \mathrm{mmol} / \mathrm{l}$ ). In the Fonnum assay (see Materials and Methods) the enzyme sample was replaced by a solution of dithiothreitol.

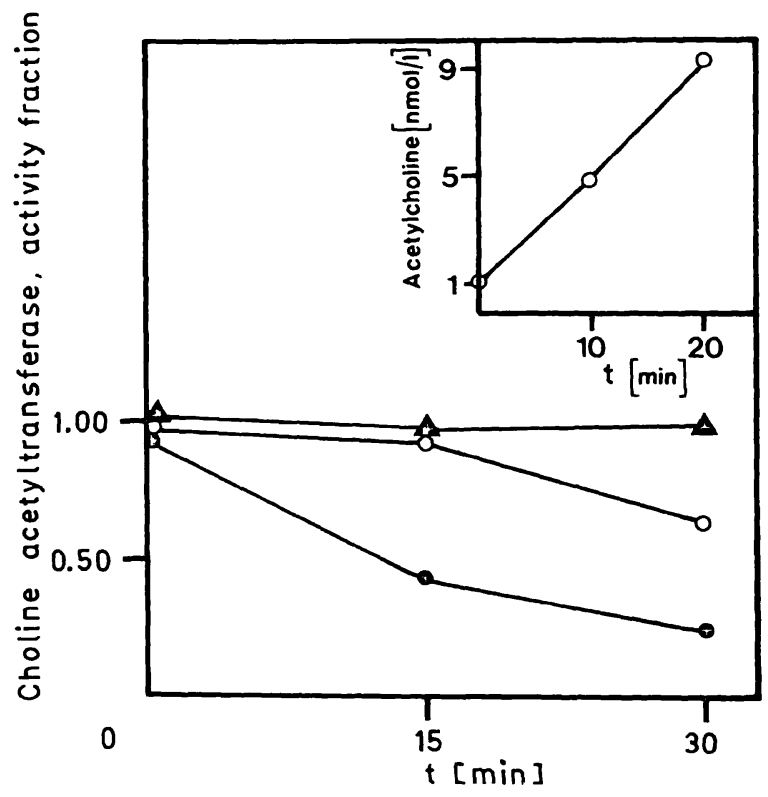

Fig. 4. Stability of choline acetyltransferase of human placenta in cerebrospinal fluid with various amounts of dithiothreitol added. $1 \mathrm{mmol} / \mathrm{l}-\Delta-, 0.1 \mathrm{mmol} / 1-0-$, or $0.01 \mathrm{mmol} / 1$ - $0-$. Insert: choline acetyltransferase like activity caused by $1 \mathrm{ml}$ of $0.1 \mathrm{mmol} / \mathrm{l}$ dithiothreitol.

fluid, the samples were concentrated tenfold as reported by other authors $(1,3)$, using a Speed Vac apparatus (Savant) which evaporates the solvent under vacuum while rotating the samples. All solvents will be concentrated equally. This technique is thought to be mild. But when choline acetyltransferase was added before concentration the recovery of activity was only about $20 \%$ of the calculated tenfold augmented value, which in turn was only twice that of the unconcentrated fluid. Inactivation and denatura- tion of proteins during concentration is a well known phenomenon of protein biochemistry (13). Comparing Speed Vac concentration with Centriflow filters (Amicon) - retention limit $M_{\mathrm{r}} 25000$ - the recovery of acetyltransferase activity was even worse. The usefulness of concentrating cerebrospinal fluid in order to detect choline acetyltransferase activity seems to be limited.

Cerebrospinal fluid and serum samples from 50 consecutive patients were studied for choline acetyltransferase activity under conditions just characterized. Each sample, unconcentrated and tenfold concentrated, was tested at $22^{\circ} \mathrm{C}$ and at $37^{\circ} \mathrm{C}$ for 10 and $20 \mathrm{~min}$. None of the samples really showed an enzymelike reaction. A very faint but significant increase in radioactive acetylcholine could be observed at $37^{\circ} \mathrm{C}$ with the concentrated samples (start: $205 \pm 41$, after $20 \mathrm{~min}: 248 \pm 41 \mathrm{nmol} / 1 \cdot \min , \mathrm{n}=50$ ). This low product formation was never found with serum or with blanks. The values measured were in the range of those found by Aquilonius \& Eckernas (3), Johnson $\&$ Domino (1), Rimon et al. (2). To check the possibility of an extremely faint enzymatic activity we therefore performed experiments to compare heated and unheated samples of cerebrospinal fluid with those inhibited with Cibacron Blue. Cibacron Blue is a potent inhibitor of choline acetyltransferase (12). In this experiment all samples except blanks show a similar increase in radioactivity (fig. 5). This result indicates a very low non-enzymatic formation of product. Choline acetyltransferase activity in cerebrospinal fluid described in the past may fall into this category. As

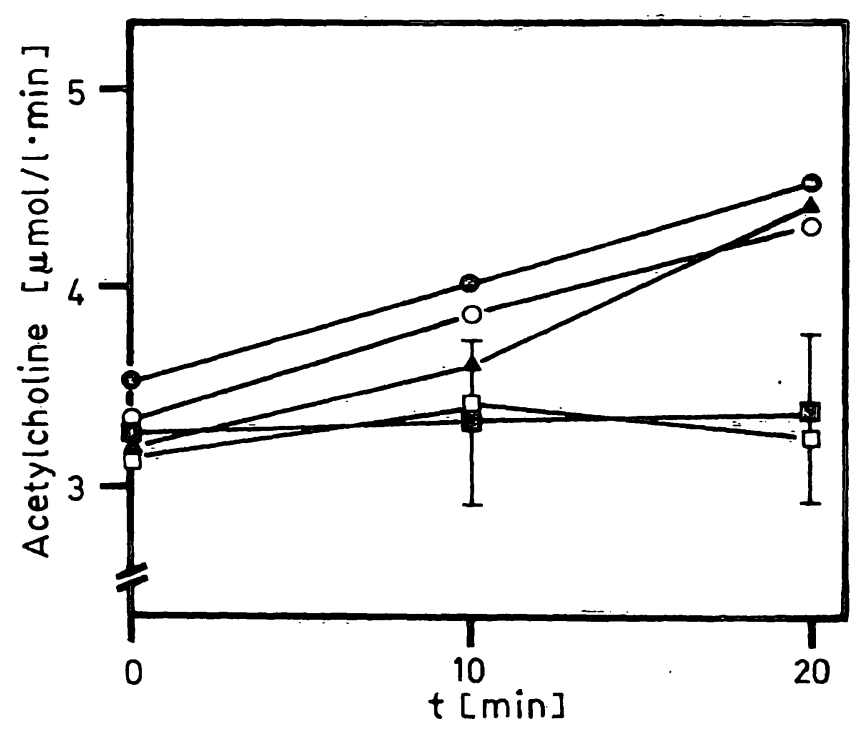

Fig. 5. Acetylcholine formation by cerebrospinal fluid. Blank (phosphate buffer, $\mathrm{pH}$ 7.4) - - -, unboiled -0boiled $-\mathbf{A}-$. Cibacron Blue inhibited cerebrospinal fluid $-\bullet-$, serum $-\square-$. 
Aquilonius \& Eckernas (3) have already pointed out, non-enzymatic formation of acetylcholine is possible, e. g. by imidazole. As we have shown, it is also possible by thiol reagents.

In conclusion no measurable amounts of choline acetyltransferase activity can be determined in human cerebrospinal fluid or serum with the very sensitive assay of Fonnum (detection limit, $0.5-1.0 \mu \mathrm{mol} /$ $1 \cdot \mathrm{min}$ acetylcholine formation). There is thus a chal- lenge to develop new methods based on immuno techniques, which will be capable of detecting traces of choline acetyltransferase molecules, even if the enzyme is inactivated.

\section{Acknowledgement}

This work was supported by the Deutsche Forschungsgemeinschaft. (SFB 330).

\section{References}

1. Johnson, S. \& Domino, E. F. (1971) Clin. Chim. Acta 35, $421-428$

2. Rimon, R., Puhakka, P., Venäläinen, E. \& Mandell, A. J. (1973) Psychiatria Fennica 19, 265-267.

3. Aquilonius, S. M. \& Eckernas, S. A. (1976) J. Neurochem. $27,317-318$.

4. Banik, N. L. \& Hogan, E. L. (1983) Cerebrospinal fluid enzymes in neurological disease. In: Neurobiology of cerebrospinal fluid (Wood, J. H., ed.) Vol. 2, Plenum Press New York, p. 211.

5. McCaman, R. E. \& Hunt, J. M. (1965) J. Neurochem. 12, $253-259$.

6. Schrier, B. K. \& Shuster, L. (1967) J. Neurochem. 14, $977-$ 985.

7. Fonnum, F. (1969) Biochem. J. 115, 465-469.

8. Fonnum, F. (1975) J. Neurochem. 24, 407-409.

9. Eckenstein, F., Barde, A. A. \& Thoenen, H. (1981) Neuroscience $6,993-1000$.

10. Chao, L. P. (1980) J. Neurosci. Res. 5, 85-115.

11. Peng, J. H., McGeer, P. L., Kimura, H., Sugn, S. C. \& McGeer, E. G. (1980) Neurochem. Res. 5, 943-962.

12. Roskoski, R., Lim, C. H. T. \& Roskoski, L. M. (1975) Biochemistry 14, 5105-5110.

13. Scopes, R. (1982) Protein Purification. Springer-Verlag New York Heidelberg Berlin.

Dr. M. Mäder

Neurologische Klinik der Universität

Robert-Koch-Straße 40

D-3400 Göttingen 
$$
\text { , }
$$ 